\title{
Partituras Imagéticas: Um diálogo Poético entre Música e Imagem
}

\author{
Imagery scores: A poetic Dialogue between Music and Image
}

\author{
Dandara Macedo Costa Dantas \\ Universidade Federal do Rio de Janeiro, Brasil \\ dantas.dandara@gmail.com
}

\author{
Celso Pereira Guimarães \\ Universidade Federal do Rio de Janeiro, Brasil \\ celsopg@ufrj.br
}

\begin{abstract}
This paper suggests a new and experimental way of visualizing music. This project turns linear information from piano sheets into a twodimensional representation. Using a symbology created to translate music data to visual plastic elements, in a metaphorical way to link sound and image, the project aims to build a music map, that could be able to picture those music data in other visualizations. Besides, this code can be used in the other way around: to create piano sheets from ready images. So, those experiences resulted in virtual images, tridimensional sculptures and new ways of creating music.
\end{abstract}

Keywords: Data visualization; Music; Visual arts; Interdisciplinarity.

\section{Introdução}

Este trabalho consiste em um recorte de minha dissertação teórico-prática que investiga e experimenta uma maneira de reorganizar o conteúdo de textos musicais disposto em formatos lineares, em composições imagéticas. Propõe-se assim uma tradução de texto em imagem, transformando linhas em superfícies musicais.

Para isso, foi criada uma simbologia para recodificar dados de partituras de piano com base em metáforas sonoro-visuais. Isto é, a visualidade foi construída a partir de uma possível e subjetiva analogia entre música e imagem, corelacionando som, pausas, ritmos, harmonias e demais informações contidas nas partituras com formas e cores.

Este artigo, portanto, procura discutir as questões em torno dessa recodificação de texto em imagens musicais e seus desdobramentos.

Assim, com base principalmente nos pensamentos de Vilém Flusser sobre filosofia da imagem, junto dos conceitos de José Miguel Wisnik sobre percepção musical, serão analisados os experimentos práticos tendo em vista seus resultados, perspectivas e potenciais de contribuição para a produção estética, tanto em termos imagéticos quanto musicais.

\section{Discussão Teórico-filosófica}

\section{Uma digressão sobre a partitura musical a partir da filosofia da imagem}

A questão que motivou esta pesquisa se deu pelo fato de a partitura musical normalmente ser considerada uma representação musical na qualidade de imagem. No entanto, ao pensar que tal notação tem o propósito de fornecer informações precisas para execução de uma determinada peça, no formato de uma narrativa explicativa, é possível considerá-la uma espécie de texto.

Para entender essa analogia entre a partitura e a escrita linear, é preciso analisar o funcionamento de textos e imagens, e comparálas à percepção da experiência musical. Para isso, será feito um aprofundamento na digressão que Flusser (1985) desenvolve sobre a origem da abstração pelo homem.

Para o autor, o homem desenvolveu imagens para se intermediar com o mundo. Essas superfícies resultaram da abstração (do mundo) de quatro dimensões em apenas duas: largura e comprimento.

Mais tarde, com o fim de aprimorar seu acesso ao mundo, o homem inventou a escrita, que na verdade acabou por afastá-los ainda mais, pelo fato de o texto exigir um trabalho de abstração ainda maior do que as imagens tanto para ser concebido, quanto decodificado. Isto é, a imagem foi criada primeiramente para codificar cenas em superfícies, e mais tarde a escrita surge para explicar tais imagens, retirar seu caráter ambíguo através de uma clara e objetiva explicação do que está contido em tais representações. Assim, de modo linear, a escrita transforma as imagens em conceitos. Por isso, diz-se que "o texto é o metacódigo das imagens" (FLUSSER, 1985)

Considerando essa diferença ontológica entre texto e imagem, é possível compreender os distintos potenciais de interação propostos por essas abstrações.

Diante de um texto, é preciso percorrer as direções e sentidos prédeterminados por suas linhas e, através do encadeamento 
sucessivo de conceitos, capta-se sua mensagem geral. Por outro lado, diante de uma pintura, é possível realizar uma síntese visual seguida de análises. Assim, no caso da imagem, é possível abarcar a mensagem em um só golpe de olhar, e depois varrê-la visualmente em direções e sentidos subjetivos, ao longo de um tempo que varia de acordo com a subjetividade do espectador. Isto é, a imagem permite uma apreensão sintética e posteriores análises de maneira livre e circular, enquanto a apreensão do texto se dá de forma linear, orientada e objetiva.

Tal contraposição reforça o caráter objetivo e restritivo das partituras. De fato, a notação musical demanda um prévio conhecimento de seu código para ser decifrada. Além disso, não pode ser apreendida em uma visualização sintética e têm caráter estritamente informativo. Assim, pode-se considerar que, da mesma forma que os textos explicam as imagens, as partituras explicam a música. Portanto, conclui-se que, assim como os textos não contém o caráter mágico das imagens, a partitura pode não conter a magia da música.

Essa interseção entre a filosofia da imagem e a percepção musical pode ser enriquecida a partir do pensamento de José Miguel Wisnik (1989). O músico complementa essa discussão ao afirmar que, com a finalidade de evitar ruídos, a partitura, de fato, se propõe a apresentar seu conteúdo de maneira precisa e inviolável. E que o som, em contrapartida, consiste em um objeto subjetivo. A partir disso, pode-se desconfiar de que a música, uma abstração subjetiva, funciona portanto de maneira bastante distinta da sua representação objetiva e hermética em forma de texto.

Nesse contexto, o contraponto pensado entre "sentido e presença" por Hans Gumbrecht (1990) muito contribui para aumentar 0 entendimento sobre as diferenças entre o funcionalismo do texto e a sensibilização pela música.

Em sua teoria, "presença" deixa de se referir ao tempo e passa a tratar do espaço, da materialidade. Nesse caso, a expressão se relaciona com os objetos "presentes" sobre os corpos humanos, as chamadas coisas do mundo.

Além do aspecto presencial dos objetos, existem suas componentes de sentido, de significação. E para o autor, essas camadas estão permanentemente sobrepostas, não podem ser isoladas. Sentido e presença convivem em constante tensão. Exceto em alguns casos, entretanto, em que se pode perceber a ascendência de uma delas: "Ao ler um texto, o sentido será predominante, enquanto que, ao ouvir uma música, a predominância estará na sensação de presença". (Gumbrecht, 1990)

Portanto, considerando que o aspecto predominantemente denotativo do texto é bastante distinto da sensação de presença musical. Com isso, conclui-se que a partitura, texto musical, não corresponde a uma representação sensível da música.
Tal discussão pode se desdobrar nos seguintes questionamentos: seria possível construir uma representação musical privilegiando aspectos da presença visual em vez da semântica do texto? Seria possível transformar os textos musicais em uma representação de caráter subjetivo, tal qual a música? Estaria a música mais próxima dos componentes imagéticos do que dos textuais?

Essas questões podem ser aprofundadas ao comparar as estruturas das linhas e superfícies com a própria música. Nesse sentido, é possível analisá-las no que tange às distintas experiências de tempo envolvidas nessas abstrações.

A estrutura da escrita constrói relações lineares de causa e efeito, gerando um tempo de apreensão relativamente mensurável durante a leitura. Por outro lado, no caso da imagem, a composição não linear permite o "eterno retorno" do olhar. Assim, ao serem percorridas pela visão de maneira circular, as imagens provocam relações de sentido reversíveis, e uma experiência de tempo subjetivo.

De forma semelhante, Wisnik sustenta que a música provoca uma sensação de tempo subjetivo, que não poderia ser mensurado pela cronologia convencional. $\mathrm{O}$ autor defende que o ritmo, por exemplo, não consiste apenas em uma sucessão linear, mas em uma oscilação de diferentes temporalidades. Manifesta-se e se ausenta como se estivesse fora do tempo, um "tempo virtual, um tempo outro". (Wisnik, 1989, p. 68)

Em encontro a esse pensamento, o filósofo Walter Gomide afirma que a música provoca uma percepção particular de tempo. À luz de Hegel e Santo Agostinho, Gomide defende que a ação musical provoca um movimento capaz de suspender a sensação de linearidade do tempo, projetando a alma para fora do presente. (Gomide, 2003, p. 40)

Assim, ao distinguir o tempo subjetivo (da imagem) do tempo cronológico (do texto), pode-se, mais uma vez, aplicar tal contraposição ao âmbito musical, para comparar a sensação de tempo proporcionado pela música e pela partitura.

Assim como no texto, a leitura de uma partitura pode ser mensurada de acordo com o tempo convencional. No entanto, a experiência proporcionada pela música aproxima-se da experiência de analisar uma imagem, no sentido de que não pode ser mensurada pela cronologia linear, consistindo portanto em uma experiência de tempo subjetivo.

Assim, ao articular os conceitos de tempo no texto, na imagem e na música segundo Flusser, Wisnik e Gomide, é possível confirmar um traço em comum entre música e imagem: ambas as abstrações promovem uma experiência de um tempo subjetivo e, portanto, imensurável. 


\section{A música como organismo}

$\mathrm{Na}$ busca por correspondências sonoro-visuais, as discussões partiam de análises sobre texto e imagem, meios através dos quais se pode representar música. Nesta etapa, entretanto, propõe-se a própria música como objeto de discussão, com fim de analisar outros conceitos e complementar os que foram abordados anteriormente.

Para isso, em vez de realizar uma análise mecanicista da música, que se apoiaria, sobretudo, nos aspectos físicos do som, ela será examinada segundo um modelo orgânico, com fim de privilegiar uma percepção fenomenológica da música.

Tal metodologia de análise foi escolhida com base no pensamento de Merleau-Ponty (2006, p. 250). O filósofo acredita que a ciência tende a condicionar a percepção humana, retirando a oportunidade de perceber um fenômeno a partir de um olhar inaugural - como diz Bachelard (1993) -, sem os vícios das atribuições de sentido já estabelecidos pelo saber científico.

Assim, quanto à ideia de totalidade, Merleau-Ponty defende que essa não se trata de uma mera soma das partes. Para o autor, esse tipo de redução acaba por limitar a análise, tendendo a considerar apenas fenômenos físico-químicos. Por outro lado, ao analisar o organismo como um conjunto, a totalidade deixa de ser passível de descrições fisiológicas e manifesta-se como emergente. (Merleay-Ponty, 1994, p. 248)

Com base nisso, pode-se retomar à comparação anterior, entre a linearidade do texto e a circularidade da imagem e chegar à diferentes ideias de totalidade nas representações musicais.

Segundo Flusser (1985), para apreensão das partituras, deve-se percorrer linha por linha para alcançar, aos poucos, todas as informações. Ou seja, a totalidade é alcançada a partir da união das partes. Entretanto, quando se trata da análise de uma imagem, a totalidade pode ser abarcada de maneira sintética, permitindo, posteriormente, análises mais detalhadas.

Diante dessa diferença envolvendo distintos meios possíveis de representação da música, é possível questionar: qual seria a relação da totalidade com as partes em se tratando da própria música?

Para José Miguel Wisnik, ritmo, melodia, durações, alturas e os demais elementos musicais não devem ser entendidos de maneiras separadas. Essa organização se dá com "um nível dependendo necessariamente do outro, um funcionando como portador do outro". O autor defende, por exemplo, que não se pode avaliar alturas, sem que elas durem minimamente. Essas variáveis são interdependentes, dialogam entre si de modo que necessitam das demais para existirem e formarem uma totalidade não por soma, mas por harmonia. (Wisnik, 1989, p. 21).
Desse modo, Wisnik nega que a totalidade musical seja percebida a partir da união das partes. Assim, diferente da partitura, com informações segmentadas que serão unidas pela leitura, pode-se dizer, em diálogo com o pensamento de Flusser, que percepção da música, por um viés orgânico e dialoga com a percepção da imagem.

Além da ideia de totalidade, o tempo musical pode ser discutido através da aproximação de música e organismo, a partir do que Wisnik chama de "metáforas corporais". Trata-se de algumas correspondências entre o som e o corpo, como uma forma de medição do tempo, aproximando a estrutura musical com a de um organismo. (WISNIK, 1989, p.19)

De forma semelhante ao som, que funciona a partir do princípio de pulsação, o autor defende que o corpo possui mecanismos de pulso, o que o torna um natural medidor de frequências. Assim, alguns povos, como os indianos, medem a duração da presença musical a partir do batimento do coração ou até mesmo do piscar dos olhos.

Ao considerar a pluralidade dos organismos, entende-se que as pulsações são de fato relativas, pois variam de acordo com cada indivíduo. Portanto, é possível deduzir que contagem do andamento da música se dá de maneira particular, diferente da contagem regular e mecanizada do metrônomo. (Wisnik, 1989, p. 20).

Assim, reunindo os conceitos de "totalidade harmônica", "complexo corpo/música para medir tempo" junto aos aspectos anteriormente analisados - como o caráter mágico, a experiência de tempo subjetivo - as correspondências entre música e imagem são fortalecidas.

Portanto, esses conceitos formam a base de sustentação teórica para a imagem musical em processo, com o fim de romper plasticamente com o código linear que normalmente assume a função de representar a música: a partitura.

\section{Partituras em multidimensões: Um vislumbre imagético}

Ao articular o pensamento de Vilém Flusser sobre filosofia da imagem, com demais teorias no campo da música e das artes visuais, constroem-se possíveis equivalências entre música e imagem. Assim, conceitos como "a predominância da presença", "liberdade de apreensão", "circularidade (não linearidade)", "totalidade harmônica" e a "temporalidade subjetiva" se tornaram a base filosófica para a compreensão das imagens musicais em desenvolvimento.

A ideia, portanto, é partir das informações contidas no texto musical e recodificá-las de modo a substituir o caráter semântico do texto pela presença imagética.

Nesse sentido, o modelo linear e objetivo da partitura pode se transformar em uma representação de potencial subjetivo e 
atemporal. E a intenção textual dá lugar, assim, a proposições imagéticas.

Dessa forma, propõe-se experimentar uma nova codificação, em que a simbologia da partitura é abandonada para dar lugar a uma composição baseada na percepção musical. Assim, formas e cores poderão dialogar com a música na construção de uma plasticidade descompromissada com a comunicação de dados quantitativos, criada apenas para fins de sensibilização estética.

Ao traduzir linhas em superfícies, então, vislumbra-se uma nova maneira de interagir com partituras musicais.

Além disso, ao trazer as superfícies para o âmbito digital, chega-se a dimensão zero, a partir da qual é possível produzir outros objetos, tanto bi quanto tridimensionais.

Assim, é possível experimentar a música em outras dimensões, tais quais os processos de abstrações discutidos por Flusser (2008): tridimensionalidade (do mundo) > bidimensionalidade (da imagem) > unidimensionalidade (do texto) > zerodimensionalidade.

Através desses processos, diferentes resultados imagéticos podem ser obtidos: Imagens bidimensionais, imagens virtuais e esculturas tridimensionais.

\section{Experimentos e Resultados}

\section{Da linha à superfície}

Para a construção do código de tradução de texto em imagem musical, com base nas discussões anteriores, as linhas horizontais das partituras passaram a se estruturar em círculos. Desse modo, a ideia de pré-orientação linear - sugerindo início, meio e fim - é então suprimida. E, assim, a percepção total e sintética da imagem se instala.

Além disso, a pausa, antes representada por elementos gráficos eventualmente presentes e ausentes na notação textual, dessa vez é representada de modo permanente. Então, o círculo de pausa passa a coincidir com o círculo principal, que simboliza o tempo não cronológico. A pausa se torna, assim, o elemento central da construção de toda a composição.

Nesse novo contexto, as notas são transferidas da partitura para a nova composição de modo ascendente ou descendente ao círculo de tempo/pausa. Essa tradução visual simboliza a percepção de a pausa estar sempre presente na música entre a duração de uma nota e outra. Dessa forma, ao ligar as notas sempre no sentido nota > pausa > nota > pausa e assim sucessivamente, tem-se a formação de uma linha, que ao se encontrar com seu outro extremo (onde se deu o início da transcrição das notas), forma uma área fechada. Logo, a organização inicialmente linear dá origem a uma superfície, e, com isso, o texto musical se transforma em imagem.

A área externa à superfície representa os sons agudos, expansivos. Por outro lado, a área interior representa os sons graves, densos, introspectivos.

Além das notas, os compassos e outras informações contidas no texto musical são igualmente traduzidas para a nova composição: através de metáforas entre a percepção musical e a plasticidade das formas visuais.

Por fim, com a forma do código definida, partiu-se para estabelecer um padrão de como as cores auxiliariam nessa tradução. No entanto, como as informações da partitura já estavam previstas no código criado, optou-se por utilizar as cores através de uma mapeamento cognitivo da peça, como uma contribuição subjetiva à visualização criada. Assim, a paleta usada para colorir cada peça foi criada a partir de sensações particulares - da própria pesquisadora - em relação às músicas mapeadas.

\section{Da superfície à linha: a tradução inversa}

A investigação em torno de modelos orgânicos de pensamento na buscar por correspondências entre música e imagem deu ainda outras contribuições. Percebeu-se que existem formas na natureza que se assemelham às imagens resultantes dos experimentos. Por conta disso, viu-se que é possível utilizar tais superfícies como in put imagético para o código criado.

Assim além da codificação anterior "Partituras em Imagens", foi possível realizar imbricações inversas: "Imagens pré-existentes em Partituras de piano".

\section{Considerações Finais}

Ao experimentar a tradução de texto musical em superfícies, e vice-versa, foi possível criar novos processos de criação imagético e musical.

Além disso, apesar de a tendência da visualização de dados envolver normalmente grandes volumes de dados objetivos com auxílio de algoritmos computacionais, a partir destas experiências, percebeu-se a potência existente também no mapeamento manual e cognitivo de informações qualitativas.

Por fim, espera-se que essas reflexões, a partir do atravessamento entre a filosofia da imagem e a música, contribuam para o pensamento e a produção de novas superfícies contemporâneas, além do fortalecimento do diálogo interdisciplinar entre o design e as artes visuais. 


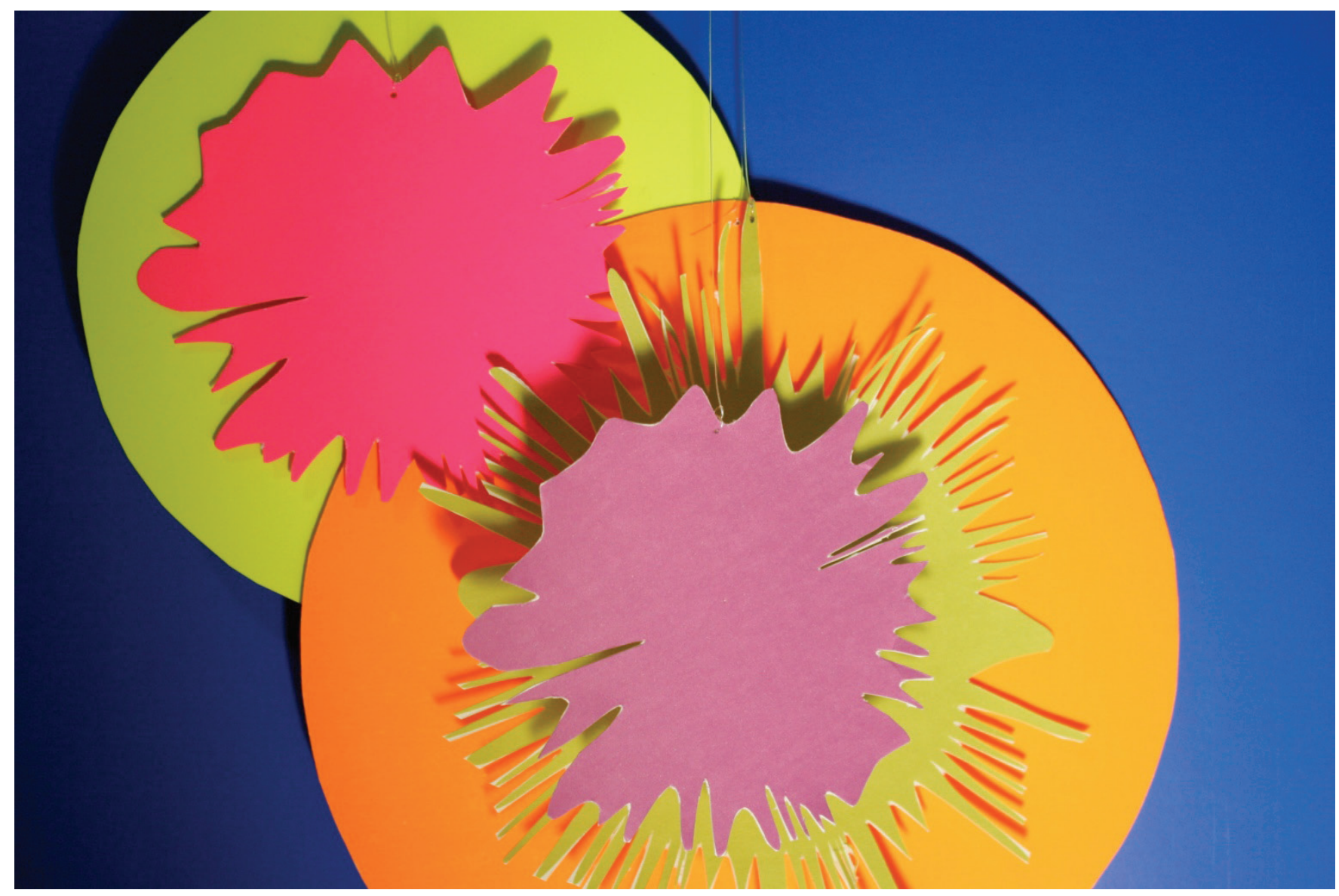

Figure 1: Registro fotográfico do primeiro protótipo de papel de escultura gerada a partir de partituras de piano.

\section{References}

Bachelard, Gaston (1993). A poética do espaço. São Paulo: Martins Fontes.

Flusser, Vilém (2008). O universo das imagens técnicas: Elogio da superficialidade. São Paulo: Annablume.

Flusser, Vilém (1985). Filosofia da caixa preta: Ensaios para uma futura filosofia da fotografia. São Paulo: Editora Rucitec.
Gomide, Walter. A Música e Três Tipos de Movimento da Alma: modalismo, tonalismo e atonalismo. (2003). O que nos faz pensar, (16), 37-52.

Gumbrecht, Hans Ulrich (2010). Produção de Presença: o que o sentido não consegue transmitir. Rio de Janeiro: Contraponto: Ed. PUC-Rio.

Merleau-ponty, Maurice (2006). A natureza. São Paulo: Martins Fontes.

Wisnik, José Miguel (1989). O som e o sentido: uma outra história das músicas. São Paulo: Companhia das Letras. 